\title{
Proposta psicopedagógica em artes visuais
}

\author{
Psychopedagogical proposal in visual arts \\ Aldicea Craveiro de Lima Ferreira*, Ana Rosa Arias Gago** \\ *Instituto Federal de Educação, Ciências e Tecnologia do Amazonas (IFAM), **Universidad de León
}

\begin{abstract}
Resumo
Este artigo registra a práxis da Modificabilidade Cognitiva Estrutural/MCE ao identificar situações de aprendizagem como, as disfunções cognitivas deficientes geradoras do fracasso escolar vivenciadas por alunos do primeiro ano do Ensino Médio. Assim, diante de larga experiência profissional de ensino, identificamos a falta das habilidades básicas de aprendizage m e co mp reensão significativas conceituais imprimidas pelos alunos que tanto os comprometiam envolvendo múltiplas disciplinas. Nesse sentido, à luz da psicopedagogia e das artes visuais, desenhou-se uma proposta sob os princípios da Experiência da Aprendizagem Mediada/EAM enquanto rota de realização das atividades educativas e culturais, balizada no aporte da pesquisa qualitativa.
\end{abstract}

Palavras chave: Artes Visuais, Fracasso Escolar, Experiência de Aprendizagem Mediada/EAM, Modificalidade Cognitiva Estrutural / MCE, Desenvolvimento Cognitivo e Emocional.

\section{Res umen}

En este artículo se registra la práctica de Modificabilidad Cognitiva Estructural / MCE para identificar situaciones de aprendizaje como la generación de disfunciones cognitivas deficientes de fracaso escolar experimentada por los estudiantes en el primer año de la escuela secundaria. Por lo tanto, ante una amplia experiencia en la enseñanza, identificó la falta de habilidades básicas de aprendizaje y comprensión conceptual significativa impresos por los estudiantes que cometieron tanto la participación de múltiples disciplinas. En este sentido, a la luz de la psicología de la educación y las artes visuales, elaboró una propuesta sobre los principios de ruta Experiencia de Aprendizaje Mediado / EAM, mientras que la realización de actividades educativas y culturales, impulsado en el suministro de la investigación cualitativa.

Palabras clave: Artes Visuales, el fracaso escolar, Experiencia de Aprendizaje Mediado / EAM, Modificalidade Estructural Cognitiva / MCE, cognitivas y desarrollo emocional.

\section{Es tado da arte}

$\mathrm{O}$ desenho da pesquisa-ação aqui imprimido traz os resultados da percepção, reflexão e compreensão das situações de aprendizagem características das funções cognitivas deficientes vivenciadas por alunos do prime iro ano do Ensino Médio, no Instituto Federal de Educação, Ciências e Tecnologia/IFAM - Campus Presidente Figueiredo, situado no interior do Estado do Amazonas. Alunos estes que, nos sensibilizaram enquanto agente social da educação, quando evidenciaram em seu prime iro ano de estudos, o Fracas so Escolar por não possuírem habilidades básicas de aprendizagem e compreensão significativas conceituais dos conteúdos da matriz curricular do Curso Técnico-Integrado em Eletrotécnica/CTIE especificamente nas disciplinas de Desenho Técnico, Artes Plásticas, Língua Portuguesa, Educação Física, Matemática, Biologia, Física e Química. Nesse contexto, a concretização investigativa que obrigatoriamente exigiu um olhar interdisciplinar na intervenção psicopedagógica desenvolvida a partir de atividades em artes visuais, compôs os estudos, levantamento de dados, análises e conclusões das variáveis protagonistas de tal fracasso, todavia, pontuados sob os princípios da Experiência da Aprendizagem Mediada/EAM enquanto rota de realização das atividades educativas e culturais, considerando a pesquisa qualitativa orientada pela investigação-ação participativa em vistas a animação sociocultural do grupo de alunos em seus princípios e naturezas de desenvolvimento educativo. Nesse processo, com a EAM obteve-se significativa Modificabilidade Cognitiva Estrutural/MCE dos alunos com potencialização de suas aprendizagens significativas nas diversas disciplinas considerando as dificuldades especificas do aprender a aprender - haja vista, no Estado do Amazonas a meta de 5,0 pontos de média de rendimento escolar, exigidos pelas institutições educativas na sua maioria, compreender-se segundo nossa visão psicopedagógica: insuficente e, sobretudo, reflexo explícito do baixo investimento financeiro na área da educação pelas autoridades brasileiras de maneira seria, processual e cientificamente correta, haja vista, todo estudante matriculado na Educação Básica, possuir pleno desenvolvimento, e, potencial cognitivo promiss or. Portanto, por fazermos parte da tarefa pública da docência em Educação Básica e formação de professores de licenciatura do IFAM, motiva-nos à pesquisa-ação, para experimentar psicopedagogicamente, a construção de novas perspectivas didáticas que atenuem e/ou previnam as dificuldades de aprendizagem vividas pelo aluno que ingressa no ensino CTIE porcons eguinte imprimindo o Fracasso Escolar. Diante dessa perspectiva de investigação-ação, os desenvolvimentos cognitivos e emocionais, a 
neurociência do aprendizado e da emoção, foram variáveis protagonizadas enquanto conteúdos de estudos necessários para o entendimento e fundamentação da ocorrência do deficit cognitivo dos alunos.

\section{Artes visuais: criando, recriando e representando o mundo}

As Artes Visuais são coisas que encantam os olhos, à med ida que, encantam a alma por nascer da possibilidade criativa de quem gosta, aprecia e produz arte. A atividade psicopedagógica em Artes Visuais desenvolveu-se dentro da perspectiva de cria e recria a representação do mundo considerando o des envolvimento sustentável que tanto se houve falar em aulas das mais diversas disciplinas nas escolas, universidades e noticiários de orientação sócio-político-ambiental. E a partir de um olhar interdisciplinar, todo o trabalho desenvolvido de início primou educação do olhar do aluno, para então, promover o desenvolvimento de atividades de produção em artes visuais que considerasse os diversos conteúdos que compusesse o curso técnico em eletrotécnica a partir do desenho, da pintura, da produção de vídeos, maquetes e recorte colagem. Esses materiais alem de serem de fácil aquisição e baixo custo ofereceu aos estudantes envolvidos, a oportunidades impar para a expressão e a expansão dos talentos artísticos, muitas vezes atenuados porque nunca tiveram acesso a atividades dess a categoria que vis lumbrasse suas dificuldades de aprendizagem em disciplinas específicas como a Biologia, a História, a Matemática, o Desenho Técnico, a Educação Física, a Geografia, a Língua Portuguesa com a Literatura e por fim as Artes Plásticas ponte entre todas. Nesse sentido, considerando a versatilidade dos materiais, podemos imaginar o grande desenvolvimento artístico que pode proporcionar o trabalho prático sob a perspectiva da manipulação desse material sob a condição da reflexão e relaxamento, muitas vezes até momentos terapêuticos, oferecidos pelo trabalho co m arte-educação, uma vezque a arte nos serve de possibilidade de alívio das tensões emocionais causadas pela sensação de incompetência intelectual na resolução de problemas conceituais referentes às atividades escolares. Por conseguinte, todo o trabalho configurou-se em u m enorme desafio, mas que se concretizou em virtude de um planejamento em projeto de ensino possível de se realiza por contar com a aceitação dos demais docentes após sensibilização que potencializou a criatividade artística dos alunos nesse início singelo do fazer artístico para superação de disfunções cognitivas deficientes sob o olhar psicopedagógico.

\section{Ensino por projetos de trabalho}

No mundo de hoje, atravessamos mudanças significativas no que concerne a captação das informações a partir da imagem $v$ isual considerando que esse fenômeno está cada vez mais presente na vida das pessoas. Nesse sentido, as imagens são apresentadas e reapresentadas a todo o mo mento, num mis to de criação e recriação. Tudo isso leva o homem que estuda e se desenvolve no reduto escolar reconhecendo a necessidade de ter competência não só para ver, mas, sobretudo, para enxergar e analisar o que ver. Para resolvero proble ma da co mplexidade da co mpreensão da arte, Fernando Hernández (2000) apresenta a proposta de ensino por projetos de trabalho, abordagem interdisciplinar e transdisciplinar da arte e da educação, que hoje se coloca entre as principais tendências pedagógicas contemporâneas da educação e do ensino da Arte, o que justifica essa proposta pedagógica de artes visuais que demonstra as reais capacidades do aluno no aprender a aprender criando, recriando e representando o mundo. As ações projetadas tiveram seu diferencial, no viés das Artes Visuais pontuando processos de valorização da imagem, material e produção em artes a partir de conteúdos temáticos, pesquisados, estudados, produzidos e representados no trabalho da oficina, apostando na autonomia e criatividade, atitude crítica e ética do aluno, à medida que, pontuava os conteúdos da História da Arte, levava conteúdo e forma do patrimônio imaterial, cultural e natural do município de Presidente Figueiredo como suporte de temas para a ação criativa nas diversas disciplinas.

\section{Dos objetivos}

Potencializar a criatividade dos alunos da turma do Curso Integrado de Eletrotécnica a partir do trabalho prático desenvolvido em oficinas de Artes Visuais com atividades diversificadas em grupo e individuais foi $o$ ápice dos trabalhos. E especificamente houve a possibilidade: de orientar estudos e pesquisas em torno de estilos e modalidades artísticas; complementar as atividades práticas da Disciplina de Artes Plásticas; formar os alunos a cerca do reconhecimento de materiais possíveis de trans formação em obra de arte; desenvolver atividades de manipulação e produção de materiais; proceder na prática de técnicas de produção artística em desenho, pintura, escultura e recorte e colagem a part ir de um tema escolhido considerado disciplina e conteúdos e objetivos de aprendizagens e, por fim, sempre procedendo em rígido avaliar processual. Nesse processo, as oficinas utilizadas em vários mo mentos de intersecção de ensino para promoção da aprendizagem em superação das dificuldades de compreensão conceitual e resolução de problemas usando as artes visuais e a ação educativa orientada em criar, e recriar o mundo imaginário, at ingiu sua principal meta: desenvolver o potencial criativo dos participantes sob o intuito de oportunizá-los a potencializar suas habilidades básicas de aprendizagem atenuando assim o fracasso escolar expressivo, mas pontual

\section{Procedimentos Metodológicos}

Do material e local de execução das aulas: as aulas realizaram-se no Auditório do IFAM-CPRF, pátio, sala de desenho; a todo o momento com formação do grupo de trabalho (através de teste de desenvoltura e criatividade gestual e especificidades criativas e escolha própria por caráter de desempenho); formação, estudos e pesquisas temáticas sob especificidades da história que cada conteúdo e temática necessitava empreender em seus aspectos simbióticos;

Elabor ação de Propostas de Dança e Teatro: dentro das atividades a dança foi um instrumento de 
desenvolvimento psicomotor que vimos proporcionar a expressão corporal flexível e direcionada a representar significados de conteúdo e forma dos assuntos envolvendo: a literatura; história; aspectos culturais estudos pela ciência geográfica e histórica. E o próprio IFAM aplicando de maneira igualitária os recursos financeiros davam condições para qualquer material necessário possível que ser adquirido chegasse às mãos dos professores colaboradores e engajados na proposta. De mu itos desses materia is podemos citar: CDs e vídeos de musicais para práticas das aulas (proposta) e aprofundamento de assuntos específicos por vídeos e documentários; Os alunos foram encorajados a sugerir através de pesquisa de interesse vídeos e documentários de suas preferências desde que não prejudique a execução da proposta clássica ou viesse desviar-lhes a atenção dos conteúdos que por obrigação deveriam ser trabalhados.

Da for mação do grupo: n núme ro de participantes no grupo, dependendo da atividade e da complexidade dos conteúdos formavam-se de até (10) alunos. Formado o grupo, aos alunos ensinavam-se conteúdos específicos preparatórios de teste de desenvoltura e potencial imediato para compor o grupo principal; em caso de trabalho envolvendo dança típica cada aluno providenciava roupas e calçados apropriados para sua participação nas aulas; não foram per permitidos alunos na prática das aulas que não estivessem com vestuário adequado, considerando que não normas do IFAM; todos os alunos sem exceção participavam das atividades devidamente dirigidas e orientadas por professor da disciplina considerando número artístico que se escolhera para ser treinado e apresentado, ou mesmo a produção de outra modalidade de produção em artes visuais que caracterizasse o conteúdo ou os conteúdos abordados na ou nas disciplinas já supracitadas. Pois ao final, a lem de estudos, pesquisas, criação, produção, aos pais fora apres entado esses resultados em vitrine cultural e científica: I vitrine cultural galo da serra: revelando talentos.

Da realização das aulas em sala por professor especifico: toda aula foi desenvolvida a princípio uma vez por semana no horário das $14 \mathrm{~h}$ às $17 \mathrm{hs}$ as sextas feiras, cada professor tomava sua necessidade de reforço de conteúdos de aprendizagem e sob a orientação especifica da professora pedagoga também formada e professora do IFAM de artes plásticas, expunha suas impressões das necessidades dos alunos que apres entavam baixo rendimento e esses eram trabalhados em atividades em processo-fólio durante o período de uma ou duas semanas de atividades de revisão e reforço dos conteúdos, mas executados pelo próprio professor. Que em seguida acumulava os resultados sob efeito imediato de recuperação paralela.

Da res ponsabilidade do aluno em participação nas aulas e nas propostas pré-elaboradas: o aluno que for participante do grupo fora sempre acompanhado pela professora e orientadora do projeto, orientado a exercer responsabilidade dirig ida na elaboração, participação e execução das propostas de estudos, pesquisas, produção e exposição segura dos seus próprios resultados; ao aluno do grupo ou em tare fa de produção individual especifica por disciplina, ao mes mo possuindo mais duas faltas seguidas sem justificativa plausível, seus responsáveis eram convocados para possível colaboração para o sucesso do aproveitamento de alunos.

Da avali ação das ati vidades: as ações pertinentes às aulas compuseram os projetos de aprendizagem e seguimos a por exposição compreensiva dos conteúdos e ou atividades propostas semperder de vista: a disciplina discente junto a assiduidade, espírito de equipe e criatividade ativa.

\section{Discursões}

A experiência de trabalhar numa perspectiva interdisciplinar tendo como pano de fundo as Artes Visuais na perspectiva da psicopedagogia - buscando-se conhecer e compreender como o principal órgão do corpo estabelece suas conexões sinápticas para assimilar conhecimento e produzir a aprendizagem significativa está para o grupo de pesquisadores como u m dos objetos de pesquisa, mais fascinadores que possa existir no contexto educativo.

A Arte em si, aqui em especial as Artes Visuais, na concepção psicopedagógica aqui compreendida, estabeleceu sem sobra de dúvida rotas de entrada, processamento e saída de informação. Esta saída em respostas maturadas - prontas a serem utilizadas pelo ensinante e aprendente na resolução de problemas complexos - tanto em sítio es colar como em situações de convívio social. Pois a Arte propicia um espaço em que se pode produzir com liberdade, isto é, livre de condicionamentos e preconceitos, não limitando a criação a meros resultados estéticos, formais conduzidos por padrões culturais específicos ou morais - é dado ao aluno a oportunidade de que experimente seu poder criativo, até mesmo sob o tema, e/ou, orientado por conteúdos integrantes do desenho curricular do seu nível de ensino sem nenhum medo de ter sua criação, determinada como estranha, feia ou desproporcional pois tudo é respeitado na condição de incluir o sujeito criador no processo - e a perfeição será por ele reconhecida, admirada e experimentada, à medida que, ele torna-se autônomo em suas percepções estéticas. E aqui estética nos remeteu a sentidos simples, o vib rar em comum, o sentir em uníssono, o experimentar coletivamente - tudo o que permite a cada sujeito, seu movimentar em ideais comunitários. Ademais, os afetos dominam os laços sociais imprimindo um vigoroso sentimento de pertença.

Desta maneira, ao perceber-se as dificuldades de aprendizagem - levando os alunos do processo, a reconhecerem suas próprias disfunções cognitivas - o trabalho de estabelecimento da ordem cognitiva dos mes mos e o poder por eles descobertos de que, existem inúmeras possibilidades em artes visuais que os levam a compreensão conceitual de conteúdos e sistemas complexos de aprendizagem - qualificou esta pesquisa-ação na condição de não só ensinarmos e democratizarmos experiências de ensino, mas, sobretudo, de entendermos que sem a pesquisa concomitante a práxis pedagógica - a educação de crianças, quiçá de 
adolescente nesse inicio de século em que, o apelo visual e virtual das imagens, configura-se $o$ ápice da problemática do desconforto e desinteresse do aluno pela escola - não é pra se estranhar o grande desdenho pela profissão de professor. Pois há um pensamento e a quase certeza das novas gerações, de que ensinar se pode e se faz, mas obter-se aprendizagem é quase que um sonho perdido - talvez is so tudo seja existente pelo descredito e pelo desconforto do povo brasileiro estar dormindo e acordando com as trágicas noticiais e situações veiculadas revelando os inúmeros escândalos políticos. Isso nos vem a mente que, no Estado do Amazonas, a Educação ainda está por produzir muitas limitações mentais, em alunos e alunas. E por quê? Por insistirem em atividades rígidas e tradicionais de ensinagem. Pois sabemos e presenciamos situações em que estes alunos e alunas, vêm à escola, cheios de expectavas, mas quase sempre, em pouco tempo, se tornam desinteressados e com baixo rendimento escolar - e por quê? Não sabemos? Ou sabemos? O que pode nos responder a essas questões? Talvez a ousadia de inovar e produzir trabalhos desafiadores e des estruturadores da 'ordem' educacional - como esta Proposta Psicopedagógica em Artes Visuais, que nos mostrou ser possível sim imprimirmos rotas significativas para o desenvolvimento global do aluno no contraponto à realidade escolar vigente que enges sa o desenho curricular dirigido à Educação Básica pelas secretarias de educação, impostas às escolas que por sua vez, despreparadas e desprovidas de um Projeto Politico Pedagógico e Participativo de Educação, que exista e seja no real executado, infelizmente.

\section{Considerações finais}

Por fim, consideramos que o homem não é só razão, mas razão versus emoção no processo ensinoaprendizagem, nesse sentido, considerar sua situação afetivo-emocional-cognitiva é impar numa perspectiva interdisciplinar e psicopedagógica - nes se caso com viés das Artes Visuais, respeitada a maneira holística da aprendizagem, vivenciada pelos alunos em pleno ato contínuo do aprender a parender. Possibilitando-os, o criar e recriar a partir dos conteúdos das diversas disciplinas, assim conquistando a compreenção do mundo no qual estão ins eridos.

\section{Ficha técnica.}

\section{Atividade: proposta psicopedagogica e $\mathrm{m}$ ar tes visuais}

A proposta: Nas oportunidades didático-pedagógicas, viu-se claramente o poder de criação que cada aluno possui e o quanto podem realizar em função do reconhecimento e superação da falta de habilidades de aprendizagem em prevenção do fracasso escolar. Em especialos da turma do Curso Integrado de Eletrotécnica, isso porque foi possível um trabalho prático desenvolvido em oficinas de Artes Visuais com atividades diversificadas em grupo e interdiscip linar sob a colaboração de quase toda a congregação de professores. Especificamente foram alcançados com excelência: Orientação de estudos e pesquis as em torno de estilos e modalidades artísticas, bem como dos estilos de aprendizagem sob uso de atividades psicopedagógicas em artes visuais com complementação orientada das atividades práticas da Disciplina de Artes Plásticas; significativa formação dos alunos a cerca do reconhecimento de suas próprias necessidades de aprendizagem - com reconhecimentos das próprias funções cognitivas deficientes; o uso intensivo de materia is passíveis de transformação em obra de arte com a representação de conteúdos temáticos e significativos para o desenvolvimento sustentável; Desenvolvimento de atividades de manipulação e produção de materiais; Pro moção na prática de técnicas de produção artística em desenho, pintura, escultura e recorte e colagem a partir de um tema escolhido pelo aluno ou réplica de obras ícones do acervo artístico das artes visuais no trabalho conjunto de artes plásticas, Historia, Geografia, Desenho Técnico, Eletricidade, Literatura e Música; Pro moção da matriz interd isciplinar na qualidade de ensinagem envolvendo as disciplinas: Educação Física, Historia Geografia, Desenho Técnico e Língua e Literatura; Avaliação do processo.

Sujeitos envolvidos: professores e 1. Ano do Ensino Técnico Integrado de Eletrotécnica.

Equipe envolvida: A ldicea Craveiro de Lima Ferreira*, Ana Rosa Arias Gago**, Maria Almerinda de Souza Matos***

Duração: Nove Meses (março a Novembro).

Recursos materiais: Cavalete $\mathrm{P} / \mathrm{p}$ intura; Pincéis pelo de marta e cerdas filmes; Bastões de tinta óleo; tinta plástica; tinta guache; Paletas; Recipientes de higienização de pincéis; Flanelas; betume; terebentina; verniz spray verniz para artesanato; papel canson; papel cuchê; pinceis atômicos finos; pincéis atômicos grossos; borrachas especiais de desenho; lápis B3, B4, B5, B6; polvilho; espátulas; bacias plásticas; moldes decorativos de madeiras; papel $40 \mathrm{~kg}$; papel dupla face; papel cartão; fita adesiva plástica; Tesouras sem ponta profissional; solvente, etc, material alternativo.

Fonte de pesquisa: livro texto, apostilas, acesso a internet em site dirigidos, manuais técnicos, documentários, visitas extra escola para levantamento de dados, filmes históricos e de ficção cientifica, biblioteca do IFAM e da Secretaria Municipal de Educação.

Avaliação: Os critérios a de avaliação constituíram-se em assiduidade, participação proativa, disciplina e responsabilidade com a qualidade prática, no desenvolvimento e produção artística, criatividade e espírito de equipe (capacidade de resolver problemas) realização e cons trução das propostas artís ticas escritas, e superação dificuldades na aprendizagem nas diversas disciplinas.

Professora res ponsável: Aldicea Craveiro de Lima,

Ferreira. email: aldicea.ferreira@ifam.edu.br

OBS: Proposta em sua $1^{\text {a }}$ Edição, Presidente Figueiredo 2013.

\section{Referências}

Bandim, J. M., Roazzi, A. \& Dom Ènech, E. (1998). Rendimento escolar em crianças com sintomas depressivos. Jornal Brasileiro de Psiquiatria, 47, 353-460. 
Bayer, H. O. (1996). O fazer psicopedagógico: a abordagem de Reuven Feurstein a partir de Piaget e Vygotsky. Porto Alegre: Meditação.

Belmonte, Lorenzo Tebar (2003). El perfil del profesor mediador. Madrid, Santillana. 4 Sección de Tercer Ciclo Postgrado Unidad de Doctorado [Type text].

Cristiano, (2002). Feuerstein e a construção mediada do conhecimento. Porto Alegre: Artmed.

Coll, C., Pozo, J.,Sarabia, B, y Valls, E. (1996). Enseñanza y aprendizaje de conceptos, procedimientos y actitudes Buenos aires: Santillana.
Del prette, A., \& Del Prette, Z.A.P. (1999). Psicologia das habilidades sociais: terapia e educação. Petrópolis: Vozes.

Dolto, F. (1999). As etapas decisivas da infância. São Paulo: Martins Fontes. Fonseca, V.; Cunha, A. C. B. (2003). Teoria da experiência de aprendizagem med iatizada e interação familiar. Lisboa: Faculdade de Motricidade Humana.

Gallego, D.J.J.G.; Gallego, A. J. A. (2004). Educar la inteligencia emocional en aula. Madrid: PPC. 